\title{
PENGARUH: FINANCIAL ATTITUDE, FINANCIAL KNOWLEDGE LOCUS OF CONTROL TERHADAP PERILAKU MANAJEMEN KEUANGAN
}

\author{
Laurensia Agustine dan Indra Widjaja \\ Program Studi Manajemen Fakultas Ekonomi dan Bisnis Universitas Tarumanagara, Jakarta \\ Email: laurensia.115170170@stu.untar.ac.id
}

\begin{abstract}
This study aims to analyze the influence of financial attitude, financial knowledge and locus of control on financial management behavior in 212 students of the Faculty of Economics and Business, Tarumanagara University. The sample was selected using convenience sampling method. The data analysis technique was using Structural Equation Models (SEM) with Smart-PLS version 3.3.3. The results of this study reveals that financial attitude and financial knowledge have an influence on financial management behavior, while locus of control have no effect on financial management behavior.
\end{abstract}

Keywords: financial attitude, financial knowledge, locus of control, financial management behaviour.

Abstrak: Penelitian ini dilakukan untuk mengetahui pengaruh financial attitude, financial knowledge dan locus of control terhadap perilaku manajemen keuangan pada 212 mahasiswa Fakultas Ekonomi dan Bisnis Universitas Tarumanagara. Teknik pemilihan sampel yang digunakan adalah metode convenience sampling. Teknik analisis data menggunakan Structual Equation Models (SEM) dengan program Smart-PLS versi 3.3.3. Hasil penelitian menunjukkan bahwa financial attitude dan financial knowledge berpengaruh terhadap perilaku manajemen keuangan, sedangkan locus of control tidak berpengaruh terhadap perilaku manajemen keuangan.

Kata Kunci: sikap keuangan, pengetahuan keuangan, tempat kendali, perilaku manajemen keuangan.

\section{LATAR BELAKANG}

Para generasi muda pada saat ini yang memasuki dunia perkuliahan seringkali tidak memiliki rasa tanggung jawab terhadap sumber dan pengelolaan keuangan yang baik. Hal ini dapat disebabkan karena remaja saat ini tumbuh di tengah - tengah budaya hutang yang difasilitasi dengan gaya dan biaya hidup yang mahal. Mereka cenderung hanya memikirkan kebutuhan jangka pendek untuk konsumsi sesaat atau melakukan praktik belanja implusif tanpa mengalokasikan penghasilan untuk kebutuhan jangka panjang yang dapat menyebabkan masalah keuangan karena kurangnya pengelolaan keuangan secara bertanggung jawab (Alexander \& Pamungkas, 2019, p. 2). Dengan adanya biaya hidup yang tinggi saat ini membuat para mahasiswa harus menyiapkan rencana keuangan dengan baik. Selain itu, mahasiswa saat ini dihadapkan pada kemandirian finansial dan mulai melakukan pengambilan keputusan yang bertanggung jawab dan cepat. Berdasarkan penelitian dari Otoritas Jasa Keuangan tahun 2019 menunjukan bahwa indeks literasi keuangan mencapai 38,03\% dan indeks inklusi keuangan 76,19\%. Hal ini dapat diartikan bahwa 38,03\% masyarakat paham mengenai jasa dan produk finansial yang digunakan. Sedangkan beberapa negara seperti 
Malaysia sudah mencapai skor $85 \%$ dari total jumlah penduduknya, sedangkan di Thailand sebesar $82 \%$. Data tersebut menyatakan bahwa tingkat literasi keuangan masyarakat Indonesia tergolong rendah. Upaya dalam peningkatan pengetahuan masyarakat mengenai keuangan dapat dilakukan dengan edukasi keuangan. Dengan adanya edukasi keuangan dini dapat membangun hal-hal positif yang dapat berguna bagi masa depan generasi muda. Menabung adalah salah satu cara untuk mengontrol penggunaan finansial seseorang untuk kebutuhan sehari-hari. Dana yang disimpan akan digunakan untuk kebutuhan masa depan (Widjaja et al., 2020, p. 3635)

Munculnya perilaku manajemen keuangan merupakan dampak dari besarnya hasrat seseorang untuk memenuhi kebutuhan hidupnya sesuai dengan tingkat pendapatan yang diperoleh (Kholilah \& Iramani, 2013, p. 70). Dengan adanya perilaku manajemen keuangan agar mereka dapat bertanggung jawab terhadap pengambilan keputusan keuangan mereka. Namun, perilaku manajemen keuangan yang baik belum cukup dilakukan bagi generasi muda khususnya mahasiswa dan mahasiswi. Kurangnya pengetahuan seseorang dapat diakibatkan oleh Pendidikan (Robb \& Woodyard, 2011, p. 60). Untuk memiliki financial knowledge, maka diperlukan pengembangan financial skill dan belajar untuk menggunakan financial tool yaitu menyiapkan anggaran, memilih investasi, memilih rencana asuransi dan menggunakan kredit. Financial tools adalah bentuk dan bagan yang dipergunakan dalam pembuatan keputusan personal financial management (Ida \& Dwinta, 2010). Selain itu, financial attitude juga dapat mempengaruhi financial management behavior. Financial attitude akan membantu seseorang dalam menentukan sikap dan perilaku mereka baik dalam hal pengelolaan keuangan, maupun sampai membuat keputusan. Faktor lain yang dapat mempengaruhi perilaku manajemen keuangan adalah locus of control. Locus of control merupakan suatu tindakan dimana seseorang menghubungkan peristiwa-peristiwa dalam kehidupannya dengan tindakan atau kekuatan dari luar kendalinya. Tujuan penelitian ini dilakukan untuk menguji sejauh mana pengetahuan dan sikap keuangan terkait dengan perilaku manajemen keuangan mahasiswa Fakultas Ekonmi dan Bisnis Universitas Tarumanagara.

\section{KAJIAN TEORI}

\section{Teori Kognitif Sosial (SCT)}

Menurut Baran \& Davis (2000) dalam penelitian (Pradiningtyas \& Lukiastuti, 2019, pp. 97-98) konsep utama dari teori kognitif sosial adalah pengertian tentang obvervational learning atau proses belajar dengan mengamati. Jika ada seorang "model" di dalam lingkungan seorang individu, misalnya teman atau anggota keluarga di dalam lingkungan internal, atau di lingkungan publik seperti para tokoh publik di bidang berita dan hiburan, proses belajar dari individu ini akan terjadi melalui cara memperhatikan model tersebut. dalam penelitian (Pradiningtyas \& Lukiastuti, 2019, p. 98), Baranowski et al., (1997) mengatakan bahwa "reinforcement is the primary construct in the operant form of learning" proses penguatan sebagai bentuk utama dari cara belajar seseorang. Di dalam teori kognitif sosial, penguatan bekerja melalui proses efek menghalangi (inhibitory effects) dan juga efek membiarkan (disinhibitory effects).

Menurut Bandura (1986) pada penelitian (Pradiningtyas \& Lukiastuti, 2019, p. 98), vicarious reinforcement terjadi karena adanya konsep pengharapan hasil (outcome expectations) dan harapan hasil (outcome expectancies). Seperti dikatakan oleh Baranowski et al., (1997) dalam penelitian (Pradiningtyas \& Lukiastuti, 2019), "People develop expectations about a situation and expectations for outcomes of their behavior before they actually encounter the situation" orang akan mengembangkan pengharapannya tentang suatu situasi 
dan pengharapannya untuk mendapatkan suatu hasil dari perilakunya sebelum seseorang benar - benar mengalamai situasi tersebut.

\section{Teori Perilaku yang Direncanakan (TPB)}

Menurut Wahyono (2014) dalam penelitian (Pradiningtyas \& Lukiastuti, 2019, p. 98) Theory of Planned Behavior (TPB) merupakan perluasan dari Theory of Reasoned Action (TRA). TRA menjelaskan bahwa niat seseorang terhadap perilaku dibentuk dari dua faktor utama, yaitu attitude toward the behavior dan subjective norms (Fishbein dan Ajzen, 1975), sedangkan dalam TPB ditambahkan satu faktor lagi, yaitu perceived behavioral control (Ajzen, 1991). TPB digunakan untuk menjelaskan berbagai perilaku didalam kewirausahaan.

\section{Financial Management Behavior}

Financial management behavior atau perilaku manajemen keuangan merupakan salah satu konsep keuangan yang sangat penting. Tujuan utama dalam pengelolaan keuangan adalah memastikan bahwa seseorang mampu mengelola keuangan serta kewajibannya secara baik.

Financial management behavior adalah kemampuan seseorang dalam mengatur perencanaan, penganggaran, pemeriksaan, pengelolaan, pengendalian, pencarian dan penyimpanan dana keuangan sehari-hari (Kholilah \& Iramani, 2013, p. 71). Munculnya financial management behavior merupakan dampak dari besarnya hasrat seseorang untuk memenuhi kebutuhan hidupnya sesuai dengan tingkat pendapatan yang diperoleh (Kholilah \& Iramani, 2013, p. 71). (Ida \& Dwinta, 2010, p. 132) menyatakan bahwa dalam pengelolaan keuangan ada hubungannya dengan tanggung jawab keuangan seseorang mengenai cara pengelolaan keuangan mereka. Seseorang yang memiliki perilaku manajemen keuangan yang cenderung membuat anggaran, menghemat uang dan dapat mengontrol pengeluaran.

Financial management behavior seseorang dapat dilihat dari empat hal (Dew \& Xiao, 2011, p. 53) yaitu :

\section{Konsumsi}

Konsumsi adalah pengeluaran oleh rumah tangga atas berbagai barang dan jasa (Mankiw, 2003). Perilaku manajemen keuangan seseorang dapat dilihat dari bagaimana ia melakukan kegiatan konsumsinya seperti apa yang di beli seseorang dan mengapa ia membelinya (Ida \& Dwinta, 2010).

2. Cash-flow Management

Cash-flow Management atau arus kas merupakan indikator utama kesehatan keuangan dengan melihat kemampuan seseorang dalam membayar semua kewajibannya. Menurut Hilgert dan Hogarth (2003) dalam penelitian (Herdjiono \& Damanik, 2016, p. 228) pengelolaan arus kas dapat diukur dari apakah seseorang membayar tagihan tepat waktu, memperhatikan catatan atau bukti pembayaran dan membuat anggaran keuangan dan perencanaan dimasa depan.

3. Saving and Investment

Menurut (Herdjiono \& Damanik, 2016, p. 228) tabungan dapat didefinisikan sebagai bagian dari pendapatan yang tidak dikonsumsi dalam periode tertentu. Karena seseorang tidak tahu apa yang akan terjadi di masa depan, uang harus disimpan untuk membayar kejadian tak terduga. Investasi merupakan salah satu hal yang penting guna untuk mengalokasikan sumber daya saat ini dengan tujuan mendapatkan manfaat di masa mendatang.

4. Credit Management

Menurut Sina (2014) dalam penelitian (Herdjiono \& Damanik, 2016, p. 229) komponen terakhir dari perilaku manajemen keuangan adalah credit management atau manajemen utang. Manajemen utang adalah kemampuan seseorang dalam memanfaatkan utang 
agar tidak membuat seseorang mengalami kebangkrutan atau menggunakan utang dalam meningkatkan kesejahteraanya.

\section{Financial Attitude}

Menurut Aydin dan Sycuk (2019) dalam penelitian (Bapat, 2020, p. 1179) sikap adalah evaluasi ide, peristiwa, objek atau orang dan memainkan peran penting di dalamnya memprediksi perilaku konsumen dalam berbagai pengaturan. Sikap keuangan berfokus pada kemampuan untuk mengendalikan diri seseorang dengan percaya pada satu hal yang dianggap baik dalam keuangan, misalnya percaya bahwa menabung itu penting (Dewi et al., 2020). Dan juga dikatakan menurut Pankow (2003) dalam penelitian (Herdjiono \& Damanik, 2016, p. 229) sikap adalah ukuran keadaan pikiran, pendapat dan penilaian seseorang terhadap dunia yang ditinggali. Sehingga financial attitude dapat diartikan keadaan, pendapat atau penilaian seseorang terhadap uang yang diterapkan kedalam sikap. Dapat disimpulkan bahwa ada suatu hubungan antara financial attitude dan masalah keuangan. Dengan demikian dapat dikatakan bahwa financial attitude seseorang juga berpengaruh terhadap cara seseorang mengatur perilaku keuangannya.

\section{Financial Knowledge}

Kehidupan yang layak dan berkualitas adalah keinginan banyak orang. Adanya keinginan para generasi muda untuk bisa membuat keputusan yang bijak dan tepat tentang bagaimana mengatur pengeluaran dan investasi hingga akhirnya memperoleh suatu tingat kekayaan. Untuk menangani keuangan pribadi seseorang secara berhasil maka diperlukan pengetahuan. Financial knowledge adalah dasar dari pengetahuan dunia keuangan. Semakin baik pengetahuan tentang keuangan makin semakin baik pula dalam mengelola keuangan (Kholilah \& Iramani, 2013, p. 72)

Seiring berkembangnya jaman, pengetahuan mengenai keuangan mulai diperkenalkan di berbagai jenjang pendidikan. Terdapat berbagai sumber pengetahuan yang dapat diperoleh, termasuk pendidikan formal seperti program sekolah tinggi atau kuliah, seminar dan kelas pelatihan di luar sekolah, serta sumber - sumber informal, seperti dari orang tua, teman, dan lingkungan pekerjaan (Ida \& Dwinta, 2010, p. 135). Untuk memiliki financial knowledge, maka perlu adanya peningkatan financial skill dan belajar untuk menggunakan financial tools.

\section{Locus of Control}

Menurut Robbins (2008:138) dalam penelitian (Kholilah \& Iramani, 2013, p. 71), Locus of Control dapat diartikan sebagai presepsi seseorang tentang sebab - sebab keberhasilan atau kegagalan dalam melaksanakan suatu pekerjaan. Locus of control menjelaskan seberapa jauh seseorang melihat hubungan antara perbuatan yang dilakukan (action) dengan akibat atau hasil (Pradiningtyas \& Lukiastuti, 2019, p. 99). Dapat disimpulkan bahwa locus of control adalah sikap dan citra diri seseorang dalam meyakini tindakannya. Rotter dalam penelitian Robbins (2008:140) membagi locus of control menjadi dua, yaitu locus of control internal dan locus of control external. Seseorang dengan locus of control internal menganggap keterampilan (skill), kemampuan (ability), dan usaha (effort) lebih menentukan hal apa yang diperoleh dalam hidup. Sedangkan locus of control external menganggap bahwa hidup itu ditentukan oleh kekuatan dari luar diri, seperti nasib, takdir keberuntungan dan orang lain yang berkuasa. 


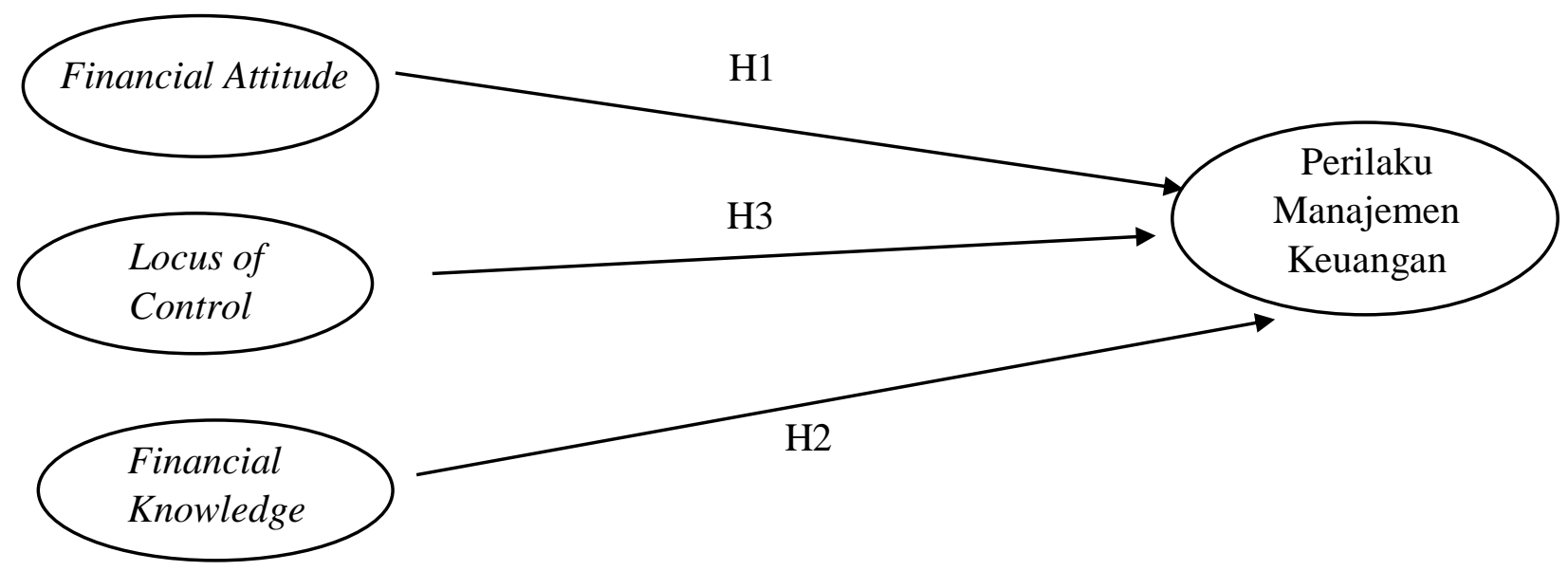

Gambar 1. Model Penelitian

H1 : Terdapat pengaruh positif antara financial attitude terhadap perilaku manajemen keuangan.

H2 : Terdapat pengaruh positif antara financial knowledge terhadap perilaku manajemen keuangan.

H3 : Terdapat pengaruh positif locus of control terhadap perilaku manajemen keuangan.

\section{METODOLOGI}

Penelitian ini menggunakan desain penelitian deskriptif dimana penelitian ini digunakan untuk menjelaskan sesuatu dengan teknik pengambilan sampel yang digunakan adalah convenience sampling. Sampel dalam penelitian ini adalah seluruh mahasiswa aktif Fakultas Ekonomi dan Bisnis Universitas Tarumanagara. Peneliti menggunakan sampel sebanyak 212 responden. Data yang akan dikumpulkan pada penelitian ini yaitu dengan kuesioner dan menggunakan skala likert. Lalu data diolah dengan menggunakan Smart-PLS versi 3.3.3. Variabel yang digunakan dalam penenelitian ini, yaitu Financial Attitude, Financial Knowledge, Locus of Control sebagai variable independen dan Perilaku Manajemen Keuangan sebagai variabel dependen.

Uji yang digunakan dalam penelitian ini adalah uji validitas dan reabilitas. Analisis data menggunakan Uji koefisien determinasi $\left(R^{2}\right)$, Uji Effect Size $\left(f^{2}\right)$ Uji Predictive Relevance $\left(Q^{2}\right)$, Uji Goodness of Fit Model dan pengujian Hipotesis menggunakan metode Bootstrapping dan Path Coefficients.

Responden yang didapatkan dalam penelitian ini berjumlah 212 orang yang dilakukan secara online melalui media sosial. Berdasarkan data yang didapatkan, mayoritas responden berjenis kelamin perempuan yaitu sebanyak 108 orang atau dengan presentase sebesar 50,9\%, berusia diantara 18 - 22 tahun yaitu sebanyak 186 orang atau dengan presentase sebesar $87,7 \%$, pendidikan SMA/SMK sebanyak 138 orang atau dengan presentase sebesar $65,1 \%$, jurusan manajemen yaitu sebanyak 189 orang atau dengan presentase sebesar $89.2 \%$, pendapatan per bulan yaitu sebanyak 118 orang atau dengan presentase sebesar $55.7 \%$. 


\section{HASIL ANALISIS DATA}

\section{Hasil Uji Validitas}

Menurut (Bougie \& Sekaran, 2013) uji validitas merupakan uji yang menentukan seberapa baik alat ukur yang digunakan untuk mengukur variabel penelitian. Dapat disimpulkan uji validitas menunjukan ketepatan antara data yang sebenarnya terjadi pada objek dengan data yang dikumpulkan oleh peneliti. Analisis validitas akan dilakukan dengan menggunakan Partial Least Square (PLS).

Tabel 1. Hasil Analisis Average Variance Extracted (AVE)

\begin{tabular}{|c|c|}
\hline Variabel & Average Variance Extracted (AVE) \\
\hline Financial Attitude & 0.645 \\
\hline Financial Knowledge & 0.620 \\
\hline Locus of Control & 0.646 \\
\hline Perilaku Manajemen Keuangan & 0.513 \\
\hline
\end{tabular}

Sumber : data yang diolah dengan Smart-PLS 3.3.3

Berdasarkan tabel 1. dapat disimpulkan nilai average variance extracted (AVE) dari variabel financial attitude, financial knoelwdge, locus of control, dan perilaku manajemen keuangan sudah di atas 0,5 yang berarti sudah memenuhi kriteria convergent validity atau valid (Kalnadi, 2013).

Pada analisis discriminant validity, hasil analisis fornell larcker untuk setiap variabel memiliki nilai yang lebih besar dari variabel lainnya. Selain itu, hasil analisis cross loading menunjukkan nilai untuk setiap indikator memiliki nilai yang lebih besar dari nilai indikator variabel lainnya. Sehingga kriteria analisis fornell-larcker dan cross loading sudah terpenuhi atau valid.

\section{Hasil Uji Reliabilitas}

Menurut (Bougie \& Sekaran, 2013), uji reliabilitas merupakan pengujian yang menentukan seberapa konsisten alat ukur yang digunakan terbebas dari kesalahan dan menunjukan hasil yang konsisten sepanjang waktu pada berbagai item dalam instrumen. Variabel dinyatakan reliabel jika memiliki nilai cronbach's alpha diatas $0,6(>0,6)$ (Malhotra, 2015) dan composite-reliability diatas 0,6 (>0,6) (Latan dan Noonan, 2017).

Tabel 2. Hasil Nilai Cronbach's Alpha

\begin{tabular}{|c|c|}
\hline Variabel & Cronbach's Alpha \\
\hline FA & 0.816 \\
\hline FK & 0.801 \\
\hline LC & 0.729 \\
\hline PMK & 0.686 \\
\hline
\end{tabular}

Sumber : data yang diolah dengan Smart-PLS 3.3.3 
Berdasarkan tabel 2. nilai dari setiap konstruk mempunyai nilai diatas 0,6 , dimana nilai cronbach's alpha pada semua variabel diatas 0,6 sehingga dapat dinyatakan reliabel dan sudah memenuhi kriteria cronbach's alpha.

Tabel 3. Hasil Nilai Composite Reliability

\begin{tabular}{|c|c|}
\hline Variabel & Composite Reliability \\
\hline FA & 0.879 \\
\hline FK & 0.866 \\
\hline LC & 0.845 \\
\hline PMK & 0.807 \\
\hline
\end{tabular}

Sumber : data yang diolah dengan Smart-PLS 3.3.3

Berdasarkan tabel 3, nilai dari setiap konstruk mempunyai nilai diatas 0,6 sehingga dapat dinyatakan reliabel dan sudah memenuhi kriteria composite reliability.

Nilai Analisis Koefisien Determinasi $\left(\boldsymbol{R}^{2}\right)$

Tabel 4. Hasil Analisis $R$-Square

\begin{tabular}{|c|c|}
\hline Variabel & R-Square \\
\hline Perilaku Manajemen Keuangan & 0.502 \\
\hline
\end{tabular}

Sumber : data yang diolah dengan Smart-PLS 3.3.3

Pada tabel diatas menunjukkan bahwa pengujian koefisien determinasi $\left(R^{2}\right)$ adalah sebesar 0,502 yang dapat disimpulkan bahwa sebesar 50,2\% dari variabel dependen yaitu perilaku manajemen keuangan dapat dijelaskan oleh variabel independen yaitu financial attitude, financial knowledge dan locus of control. Sisanya sebesar 49,8\% dijelaskan oleh variabel-variabel lain di luar penelitian ini. Nilai R-square sebesar 0,502 tergolong moderat.

\section{Hasil Uji Predictive Relevance $\left(Q^{2}\right)$}

Tabel 5. Hasil Predictive Relevance

\begin{tabular}{|c|c|}
\hline Variabel & Predictive Relevance \\
\hline Perilaku Manajemen Keuangan & 0.241 \\
\hline
\end{tabular}

Berdasarkan tabel diatas, nilai $Q^{2}$ adalah sebesar 0,241. Penelitian yang baik memiliki nilai $Q^{2}>0$.Hal ini dapat disimpulkan bahwa perilaku manajemen keuangan bersifat relevan dan dapat digunakan untuk mengukur suatu model penelitian yang sudah dibentuk.

\section{Hasil Uji Effect Size $\left(f^{2}\right)$}

Tabel 6. Hasil Uji Effect Size

\begin{tabular}{|c|c|}
\hline Variabel & Perilaku Manajemen Keuangan \\
\hline Financial Attitude & 0.252 \\
\hline Financial Knowledge & 0.137 \\
\hline Locus of Control & 0.015 \\
\hline
\end{tabular}


Berdasarkan tabel 6, menunjukkan hasil perhitungan dimana dapat dijelaskan bahwa variabel financial attitude dan financial knowledge memiliki pengaruh perubahan yang sedang dengan masing-masing nilai sebesar 0,252 dan 0,137. Sedangkan variabel locus of control menunjukkan pengaruh perubahan yang kecil dengan nilai sebesar 0,015 .

\section{Hasil Uji Goodness of Fit}

$$
\begin{aligned}
& \text { GoF }=\sqrt{A V E x R^{2}} \\
& \mathrm{AVE}=\frac{0.645+0.620+0.646+0.513}{4}=0.606 \\
& \mathrm{GoF}=\sqrt{A V E \times R^{2}} \\
& \mathrm{GoF}=\sqrt{0.606 \times 0.502}=0.5516
\end{aligned}
$$

Berdasarkan hasil perhitungan GoF diatas, dapat disimpulkan bahwa penelitian ini memiliki nilai GoF yang besar.

\section{Hasil Pengujian Hipotesis}

Tabel 7. Hasil Pengujian Hipotesis

\begin{tabular}{|c|c|c|c|}
\hline Variabel & $\begin{array}{c}\text { Path } \\
\text { Coefficients }\end{array}$ & t-statistics & p-values \\
\hline $\begin{array}{c}\text { Financial Attitude -> } \\
\text { Perilaku Manajemen } \\
\text { Keuangan }\end{array}$ & 0.417 & 6.643 & 0.000 \\
\hline $\begin{array}{c}\text { Financial Knowledge -> } \\
\text { Perilaku Manajemen } \\
\text { Keuangan }\end{array}$ & 0.329 & 4.437 & 0.000 \\
\hline $\begin{array}{c}\text { Locus of Control -> } \\
\text { Perilaku Manajemen } \\
\text { Keuangan }\end{array}$ & 0.115 & 1.394 & 0.164 \\
\hline
\end{tabular}

Berdasarkan tabel 7, dapat disimpulkan bahwa nilai path coefficients menunjukkan nilai prediksi variabel financial attitude memiliki arah yang positif sebesar 0,417 , nilai prediksi financial knowledge memiliki arah yang positif sebesar 0,329, dan nilai prediksi locus of control memiliki arah yang positif sebesar 0,115 .

\section{DISKUSI}

Hasil pengujian ini menunjukkan terdapat pengaruh postitif financial attitude terhadap perilaku manajemen keuangan. Hal ini dapat dilihat dari nila $p$-values 0,000 dimana nilai tersebut lebih kecil dari 0,05. Dan nilai t-statistics nya sebesar 6,643, dimana nilai tersebut lebih besar dari 1,96. Sehingga dapat disimpulkan H1 diterima. Effect size dari financial attitude adalah sebesar 0,252 dimana variabel ini memiliki efek perubahan yang sedang.

Hasil pengujian ini menunjukkan terdapat pengaruh positif financial knowledge terhadap perilaku manajemen keuangan. Hal ini dapat dilihat dari nilai $p$-values sebesar 0,000 
yang dimana nilai tersebut lebih kecil dari 0,05. Dan nilai $t$-statistics nya sebesar 4,437 dimana nilai tersebut lebih besar dari 1.96. Sehingga dapat disimpulkan bahwa $\mathrm{H} 2$ diterima. Effect size dari financial knowledge adalah sebesar 0,137 dimana variabel ini memiliki efek perubahan yang sedang.

Hasil pengujian ini menunjukkan tidak terdapat pengaruh locus of control terhadap perilaku manajemen keuangan. Hal ini dapat dilihat dari nilai $p$-values sebesar 0,164 yang dimana nilai tersebut lebih besar dari 0,05. Dan nilai $t$-statistic nya sebesar 1,394 dimana nilai tersebut lebih kecil dari 1,96. Sehingga dapat disimpulkan H3 ditolak. Effect size dari locus of control adalah sebesar 0,015 dimana variabel ini memiliki efek perubahan yang kecil atau lemah.

\section{KESIMPULAN}

Kesimpulan yang dapat diambil pada hasil yang dilakukan pada penelitian ini adalah financial attitude dan financial knowledge memiliki pengaruh secara positif terhadap perilaku manajemen keuangan. Namun, locus of control tidak terdapat pengaruh terhadap perilaku manajemen keuangan.

Berdasarkan hasil penelitian yang sudah dilakukan, peneliti menyarankan mahasiswa Fakultas Ekonomi dan Bisnis Universitas Tarumanagara untuk belajar cara merencanakan dan mengatur keuangan agar kelak di masa depan lebih terpenuhi dan peningkatan sikap dan pengetahuan dalam mengelola keuangan.

Untuk peneliti selanjutnya, disarankan dapat menambahkan jumlah variabel independen dan yang mempengaruhi perilaku manajemen keuangan sehingga hasil yang didapatkan bias menjadi lebih baik dan bermanfaat. Lalu disarankan untuk melakukan penelitian secara langsung (bukan dengan kuisioner online). Pengisian kuisioner secara offline, mendorong keseriusan dari para responden dalam pengisian kuisioner. Disarankan juga untuk dapat memperluas ruang lingkup penelitian sehingga tidak terbatas hanya perilaku manajemen keuangan pada mahasiswa/ mahasiswi.

\section{DAFTAR PUSTAKA}

Alexander, R., \& Pamungkas, A. S. (2019). Pengaruh Pengetahuan Keuangan, Lokus Pengendalian Dan Pendapatan Terhadap Perilaku Keuangan. Jurnal Manajerial Dan Kewirausahaan, $1(1), \quad 157-164$. https://journal.untar.ac.id/index.php/JMDK/article/view/2798

Amanah, E., Iradianty, A., \& Rahardian, D. (2016). The Influence of Financial Knowledge, Financial Attitude and External Locus of Control on Personal Financial Management Behavior Case Study of Bachelor Degree Student in Telkom University. E-Proceeding of Management, 3(2), 1228-1235.

Anuraga, G., Sulistiyawan, E., \& Munadhiroh, S. (2017). Structural Equation Modeling - PLS Untuk Pemodelan IPKM Jawa Timur. 257-263.

Bapat, D. (2020). Antecedents to responsible financial management behavior among young adults: moderating role of financial risk tolerance. International Journal of Bank Marketing, 38(5), 1177-1194. https://doi.org/10.1108/IJBM-10-2019-0356

Borden, L. M., Lee, S. A., Serido, J., \& Collins, D. (2008). Changing college students' financial knowledge, attitudes, and behavior through seminar participation. Journal of Family and Economic Issues, 29(1), 23-40. https://doi.org/10.1007/s10834-007-9087-2

Bougie, \& Sekaran. (2013). Research Methods for Business: A skill Building Approach. John wiley@Sons. 
Dew, J., \& Xiao, J. J. (2011). The financial management behavior scale: Development and validation. Journal of Financial Counseling and Planning, 22(1), 43-59.

Dewi, V. I., Febrian, E., Effendi, N., \& Anwar, M. (2020). Financial literacy among the millennial generation: Relationships between knowledge, skills, attitude, and behavior. Australasian Accounting, Business and Finance Journal, 14(4), 24-37. https://doi.org/10.14453/aabfj.v14i4.3

Elliehausen, G., Lundquist, E. C., \& Staten, M. E. (2007). The impact of credit counseling on subsequent borrower behavior. Journal of Consumer Affairs, 41(1), 1-28. https://doi.org/10.1111/j.1745-6606.2006.00066.x

Hair, J. F., Sarstedt, M., Hopkins, L., \& Kuppelwieser, V. G. (2014). Partial least squares structural equation modeling (PLS-SEM): An emerging tool in business research. European Business Review, 26(2), 106-121. https://doi.org/10.1108/EBR-10-2013-0128

Herdjiono, I., \& Damanik, L. A. (2016). Pengaruh Financial Attitude,Financial Knowledge, Parental Income Terhadap Financial Management Behavior. Jurnal Manajemen Teori Dan Terapan| Journal of Theory and Applied Management, 9(3), 226-241. https://doi.org/10.20473/jmtt.v9i3.3077

Ida, \& Dwinta, C. Y. (2010). Pengaruh Locus Of Control, Financial Knowledge, Income Terhadap Financial Management Behavior. Jurnal Bisnis Dan Akuntansi, 12(3), 131144.

Kholilah, N. Al, \& Iramani, R. (2013). Studi Financial Management Behavior Pada Masyarakat Surabaya. Journal of Business and Banking, 3(1), 69. https://doi.org/10.14414/jbb.v3i1.255

Lee, H. W. (2013). Locus of control, socialization, and organizational identification. Management Decision, 51(5), 1047-1055. https://doi.org/10.1108/MD-11-2012-0814

Malhotra, N. (2015). Essentials of Mrketing Research: A Hands-On Orientation. Perason Education.

Mien, N. T. N., \& Thao, T. P. (2015). Factors Affecting Personal Financial Management Behaviors Evidence from Vietnam. Proceedings of the Second Asia-Pacific Conference on Global Business, Economics, Finance and Social Sciences (AP15Vietnam Conference). https://doi.org/10.1161/01.HYP.0000200705.61571.95

Paluri, R. A., \& Mehra, S. (2016). Financial attitude based segmentation of women in India: an exploratory study. International Journal of Bank Marketing, 34(5), 670-689. https://doi.org/10.1108/IJBM-05-2015-0073

Pradiningtyas, T. E., \& Lukiastuti, F. (2019). Pengaruh Pengetahuan Keuangan dan Sikap Keuangan terhadap Locus of Control dan Perilaku Pengelolaan Keuangan Mahasiswa Ekonomi. Jurnal Minds: Manajemen Ide Dan Inspirasi, 6(1), 96. https://doi.org/10.24252/minds.v6i1.9274

Ramalho, T. B., \& Forte, D. (2019). Financial literacy in Brazil - do knowledge and selfconfidence relate with behavior? RAUSP Management Journal, 54(1), 77-95. https://doi.org/10.1108/RAUSP-04-2018-0008

Riitsalu, L., \& Murakas, R. (2019). Subjective financial knowledge, prudent behaviour and income: The predictors of financial well-being in Estonia. International Journal of Bank Marketing, 37(4), 934-950. https://doi.org/10.1108/IJBM-03-2018-0071

Robb, C. A., \& Woodyard, A. S. (2011b). Financial Knowledge and Best Practice Behavior. Journal of Financial Counseling and Planning, 22(1), 60-70.

Saurabh, K., \& Nandan, T. (2018). Role of financial risk attitude and financial behavior as mediators in financial satisfaction: Empirical evidence from India. South Asian Journal of Business Studies, 7(2), 207-224. https://doi.org/10.1108/SAJBS-07-2017-0088

Sugiyanto, T., Radianto, W. E., Efrata, T. C., \& Dewi, L. (2019). Financial Literacy, Financial 
Attitude, and Financial Behavior of Young Pioneering Business Entrepreneurs. 100(Icoi), 353-358. https://doi.org/10.2991/icoi-19.2019.60

Widjaja, I., Arifin, A. Z., \& Setini, M. (2020). The effects of financial literacy and subjective norms on saving behavior. Management Science Letters, 10(15), 3635-3642. https://doi.org/10.5267/j.msl.2020.6.030

Yap, R. J. C., Komalasari, F., \& Hadiansah, I. (2016). The Effect of Financial Literacy and Attitude on Financial Management Behavior and Satisfaction. International Journal of Administrative Science \& Organization, 23(3), 140-145. 